\title{
Progress in Flaps Down Flight Reynolds Number Testing Techniques at the NTF
}

\author{
Frank Payne ${ }^{*}$ and Cris Bosetti ${ }^{\dagger}$ \\ The Boeing Company, Seattle, Washington 98124 \\ Greg Gatlin^, Dave Tuttle", and Bob Griffiths \\ NASA Langley Research Center, Hampton, Virginia 23681
}

\begin{abstract}
A series of NASA/Boeing cooperative low speed wind tunnel tests was conducted in the National Transonic Facility (NTF) between 2003 and 2004 using a semi-span high lift model representative of the 777-200 aircraft. The objective of this work was to develop the capability to acquire high quality, low speed (flaps down) wind tunnel data at up to flight Reynolds numbers in a facility originally optimized for high speed full span models. In the course of testing, a number of facility and procedural improvements were identified and implemented. The impact of these improvements on key testing metrics - data quality, productivity, and so forth - was significant, and is discussed here, together with the relevance of these metrics as applied to cryogenic wind tunnel testing in general. Details of the improvements at the NTF are discussed in AIAA-2006-0508 ("Recent Improvements in Semi-span Testing at the National Transonic Facility"). The development work at the NTF culminated with validation testing of a 787-8 semi-span model at full flight Reynolds number in the first quarter of 2006.
\end{abstract}

\section{Nomenclature}

$\begin{array}{ll}\text { atm } & =\text { atmospheres } \\ { }^{\circ} \mathrm{C} & =\text { degrees Centigrade } \\ \mathrm{CFD} & =\text { Computational Fluid Dynamics } \\ \mathrm{C}_{\mathrm{Lmax}} & =\text { maximum lift coefficient } \\ \mathrm{C}_{\mathrm{L} 6} & =\text { lift coefficient at } 6^{\circ} \text { angle of attack } \\ \mathrm{C}_{\mathrm{DP} 6} & =\text { profile drag coefficient at } 6^{\circ} \text { angle of attack } \\ \mathrm{Cp} & =\text { coefficient of pressure } \\ \mathrm{cu} \mathrm{ft} & =\text { cubic feet } \\ { }^{\circ} \mathrm{F} & =\text { degrees Fahrenheit } \\ \mathrm{Rn} & =\text { Reynolds number (based on mean aerodynamic chord) } \\ \mathrm{ppm} & =\text { parts per million (based on volume ratio) } \\ \mathrm{LaRC} & =\text { Langley Research Center } \\ \mathrm{M} & =\text { Mach number } \\ \mathrm{NASA} & =\text { National Aeronautics and Space Administration } \\ \mathrm{NTF} & =\text { National Transonic Facility } \\ \mathrm{Pt}(\mathrm{psia}) & =\text { tunnel total pressure in pounds per square inch } \\ \mathrm{PSF} & =\text { pounds per square foot } \\ \mathrm{Q}, \mathrm{q} & =\text { dynamic pressure } \\ \mathrm{TI} & =\text { tolerance interval } \\ \mathrm{Tt}(\mathrm{degF}) & =\text { tunnel total temperature in degrees Fahrenheit }\end{array}$

* Engineer/Scientist, 787 High Lift Aerodynamics, PO Box 3707, MC 02-XJ, Senior Member AIAA.

${ }^{\dagger}$ Engineer/Scientist, 787 High Lift Aerodynamics, PO Box 3707, MC 02-XJ.

${ }^{\wedge}$ Research Engineer, Configuration Aerodynamics Branch, Mail Stop 267, Senior Member AIAA.

${ }^{\#}$ Facility Engineer/Test Engineer, Arc Heated Scramjet Test Facility, Mail Stop 168.

$*$ Senior Project Manager, 14x22 Foot Subsonic Wind Tunnel, Mail Stop 289, Senior Member AIAA 


\section{Introduction}

As reflected in its name, the National Transonic Facility (NTF) is a high speed (transonic) wind tunnel capable of attaining flight or near flight Reynolds numbers by testing sub-scale models at high pressure and low (cryogenic) temperatures. For the first fifteen years of its operation, virtually all of the commercial aircraft configurations tested at the facility were sting-mounted full span models. Improvements phased in over the last decade now make it possible to test low speed (flaps down) semi-span models at up to flight Reynolds number. Although it can be expensive to conduct lengthy preliminary design studies at such a facility (due to the cost and cycle time involved with making numerous configuration changes), using a cryogenic wind tunnel to evaluate the Reynolds number sensitivity of new technology, appraise selected preliminary designs, and/or verify the final design can be a cost effective way to reduce the risk of unanticipated results in a subsequent flight test program.

Early in the low speed aerodynamic design of the Boeing 787-8 airplane, it was recognized that flight Reynolds number validation testing $\left(\mathrm{Rn} \sim 24 \times 10^{6}\right)$ would be a valuable addition to the intensive mid-Reynolds-number $\left(\mathrm{Rn} \sim 6 \times 10^{6}\right)$ configuration development testing already scheduled for the QinetiQ-5m pressure tunnel. In anticipation of 787 validation testing, and building on foundational semi-span testing work conducted at the NTF in $2000^{1}$, a series of low speed tests using an existing 777-200 semi-span model was conducted at the NTF in the 20032004 time period to study Reynolds number effects, build a database for assessment of CFD models, validate evolving design and analysis methods, and evaluate ongoing facility improvements. This paper discusses results from the 777 model testing and includes an explanation of issues unique to low speed cryogenic testing, as well as a brief discussion of key results from the initial 787-8 entry at the NTF in the first quarter of 2006.

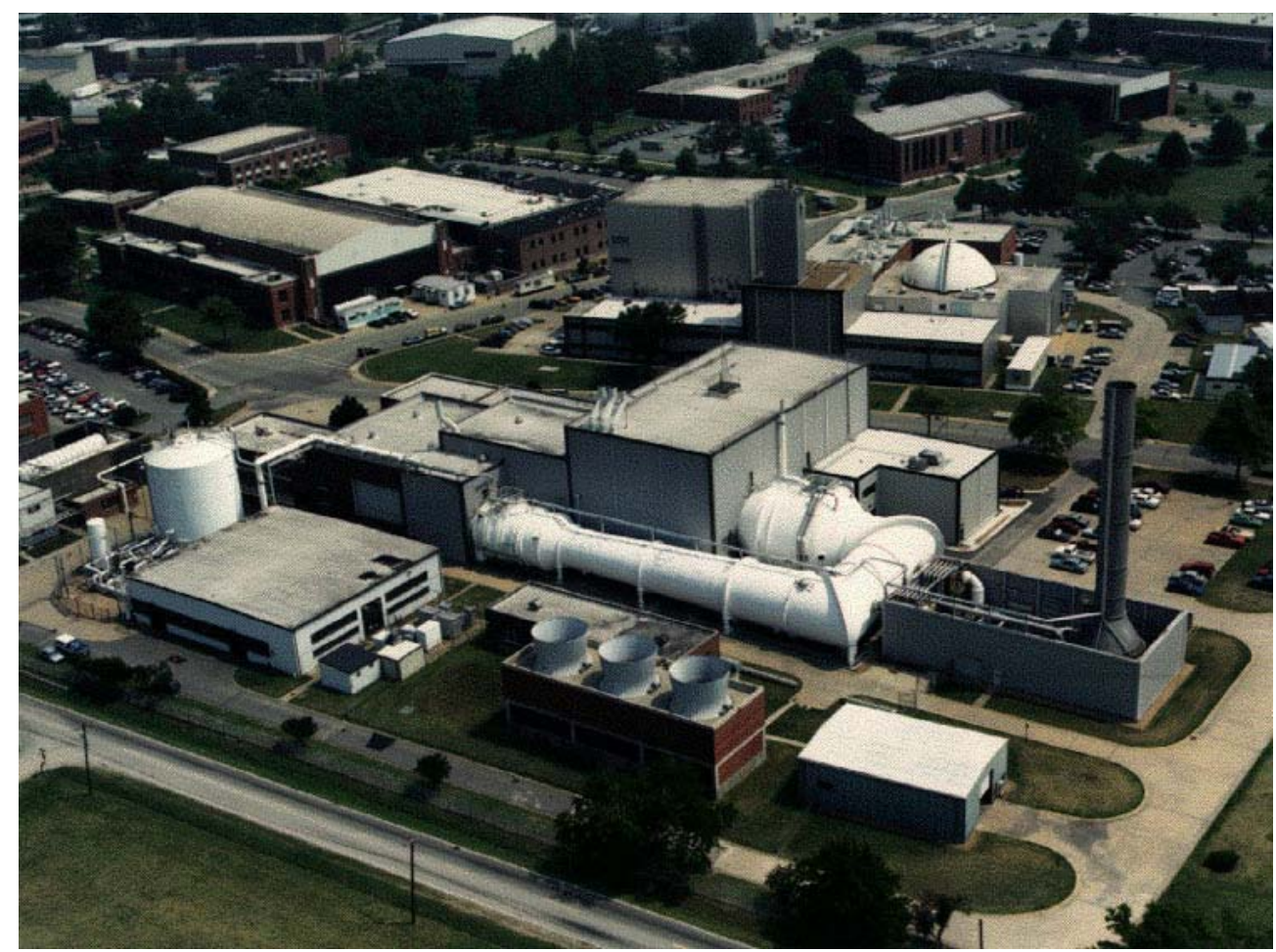

Figure-1. National Transonic Facility

(Photo courtesy of NASA Langley Research Center)

\section{Background}

When the NASA LaRC National Transonic Facility opened in 1984, it was the first continuous flow aerodynamic research facility in the world capable of achieving flight Reynolds numbers on a commercial transport at transonic Mach numbers (Fig.1). The facility has a test section size of $8.2 \times 8.2 \mathrm{ft}$, a Mach number range of 0.2 to 1.2 , a total pressure capability of more than 8 atmospheres, and a total temperature range of $+150^{\circ}$ to $-260^{\circ} \mathrm{F}$. The combination of transonic Mach number, high pressure, and low temperature allows Reynolds numbers of up to approximately 40 million per foot at Mach 0.21 or 146 million per foot at Mach 1.0. Additionally, the availability of 
temperature as a variable allows separation of aeroelastic (dynamic pressure) effects from true Reynolds number effects. Understandably, for the first decade of its operation, the focus at the NTF was directed almost exclusively at cruise (i.e. transonic) research using full span models.

Beginning around 1994, however, researchers at NASA and within the aerospace community at large began to recognize the need for a low speed capability to explore the largely uncharted flight Reynolds number regime encountered by wind tunnel models configured for flaps down (takeoff and landing) operations ${ }^{2}$. The NTF responded with development of new hardware (a semi-span model installation), instrumentation (an external sidewall balance), and a host of new test techniques ${ }^{3-8}$. The inspiration for this paper was the experience gained during three cooperative low speed wind tunnel tests conducted by NASA and Boeing in the 2003-2004 time period to evaluate the status of this work.

Today, high quality aerodynamic data can be obtained at the NTF with full or semi-span models, at high or low Mach numbers, in air or nitrogen, and with ever increasing efficiency. The NTF staff is working hard to expand the traditional role of the tunnel as a dedicated high Reynolds number research facility to better compete with conventional (non cryogenic) production wind tunnels (optimized for rapid model changes and high throughput). The goal of improved efficiency is driving yet another round of facility improvements with the objective of reducing model installation time, model change time, and cryogenic conditioning time. The success of this latest initiative will be crucial in keeping the tunnel a viable resource well into the $21^{\text {st }}$ century.

\section{Low Speed Configuration Development}

The aerodynamic design environment at Boeing and other major aerospace manufacturers depends on a complex mix of CFD tools and trusted wind tunnel facilities. Computational codes can range from simple (2D, inviscid) to highly complex (3D, Navier Stokes), just as wind tunnels can range from small atmospheric flow through facilities to large cryogenic pressure tunnels. Given the reality of finite budgets, it is imperative to match the need for quality aerodynamic data to the simplest, most cost effective source that can provide it. Accurate, repeatable data are assumed. Reliable access to the facility when needed is also a prerequisite. Boeing uses low and moderate Rn wind tunnels to build large data bases, and high (flight) Rn facilities to investigate scale effects, validate CFD codes, and evaluate new design concepts.

\section{Role of Flight Reynolds Number Testing}

Development of the low speed configuration (high lift devices) for a modern commercial transport requires two or three design and validation cycles, each of which is linked to one or more wind tunnel tests. The milestones associated with these wind tunnel tests essentially dictate the overall program schedule. Reducing wind tunnel flow times can therefore have a huge impact on overall program cost and schedule 9

Early in the jet age $(707,727)$, virtually all Boeing low speed configuration development testing was conducted in atmospheric wind tunnels at low Reynolds numbers ( $\sim 1$ to 2 million). For later models (737, 747, 757, 767), a "mid" Rn $\left(\sim 6 \times 10^{6}\right)$ validation cycle was added. By the time the 777-200 was designed (in the early 1990s), the split between low and mid Rn testing had become about 50/50, with most trailing edge development done at low Rn, and most leading edge development at mid Rn. The trend toward ever higher Rn has continued with the 787 program where close to $100 \%$ of low speed development work (both leading and trailing edge) has been conducted at mid Rn $\left(\sim 6 \times 10^{6}\right)$ and, for the first time within a development program, "flight" $\mathrm{Rn}\left(\sim 24 \times 10^{6}\right)$ validation testing has been added. Projecting this trend into the future strongly suggests an expanding role for flight Rn testing, though the degree to which cryogenic facilities are used for developmental (as opposed to validation or research testing) remains to be seen. The answer is partly dependent on resolution of the frequently repeated question, "How much Reynolds number is enough?" In other words, how high a Reynolds number is really needed for engineers to accurately predict low speed performance in flight? Answering that question is one of the fundamental goals of aerodynamic research in the present decade. Technical issues aside, the answer to this question will have major implications for industrial wind tunnel operators around the world. Whatever the answer, it is already known that wind tunnel customers prefer to test as close to the projected flight value as possible. How much they test at flight $\mathrm{Rn}$ - and in which facilities - depends on the quality of the data, the efficiency of the facility, and the cost of testing.

\section{Low Speed Research at the NTF}

A series of low speed (high lift) configuration tests utilizing an existing 777-200 semi-span model was conducted early in the present decade (Table 1) to evaluate low speed processes under development at the NTF and

to gather data on the "How much Rn is enough" question. A number of challenges were encountered in the course of 
the testing and are described below (see Section VI, Low Speed Cryogenic Testing Challenges). The work culminated in the testing of a 787 cryogenic model in the first quarter of 2006.

The model used for the majority of the testing was a $5.2 \%$ scale $777-200$ semi-span model designed and built by Micro Craft Inc. in 1999. The model was mounted on the tunnel sidewall with a non-metric standoff plate as shown in Fig.-2. Separate leading and trailing edge flap assemblies were fabricated for takeoff and landing configurations. The wing, nacelle, and nacelle strut are made of Vascomax C200 maraging steel.

Table-1. Low Speed Research Tests at the NTF

\begin{tabular}{|c|c|c|}
\hline Test & Model & Year \\
\hline NTF-144 & $777-200$ & August 2003 \\
NTF-145 & $777-200$ & December 2003 \\
NTF-150 & $777-200$ & October 2004 \\
NTF-162 & $787-8$ & March 2006 \\
\hline
\end{tabular}

The 787-8 model (Fig. 3) was built by Aircraft Research Association, Ltd. (ARA), based in the United Kingdom, with Mitsubishi Heavy Industries (MHI) of Japan, as a major sub-vendor. ARA fabricated the wing, fuselage, trailing edge high lift system, and support structure; whereas MHI fabricated the horizontal tail, incidence blocks, and leading edge high lift system.

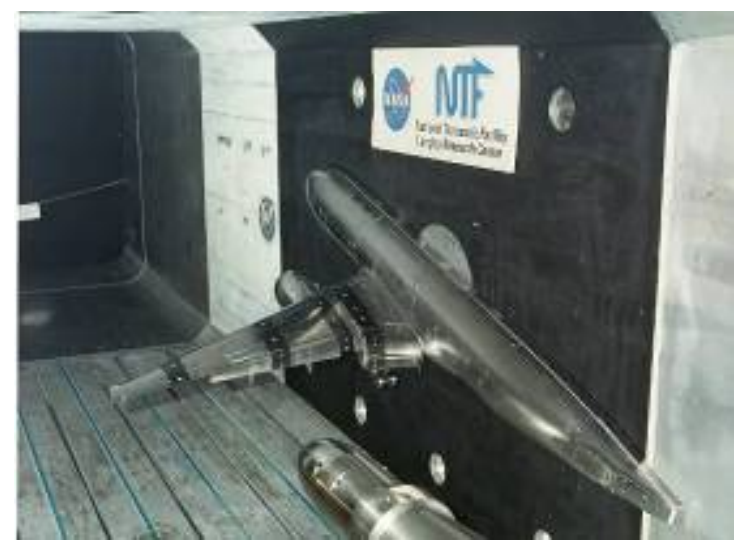

Figure-2. 777 Model in the NTF Test Section

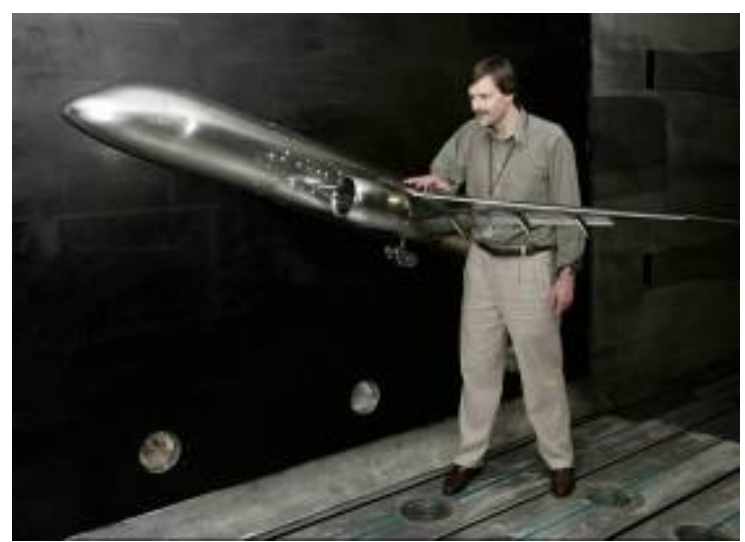

Figure-3. 787 Model in the NTF Test Section

The data shown in Table 2 illustrate the progress made at the NTF on cryogenic low speed testing techniques between August 2003 and March 2006. The table compares 95\% tolerance intervals for three representative aerodynamic coefficients $\left(\mathrm{C}_{\mathrm{Lmax}}, \mathrm{C}_{\mathrm{L} 6}\right.$, and $\left.\mathrm{C}_{\mathrm{DP} 6}\right)$ with "good practice" target values from Ref. 9 for a model configured with maximum landing flaps. The tolerance intervals are based on sets of 3 to 13 repeat runs extracted from 1 to 3 repeat series from each of the indicated tests, where a "series" is all of the runs for a given model configuration. Tolerance intervals are a measure of the predicted scatter in the data after adjusting for the number of points actually acquired. (If only a few points are acquired, the true scatter is likely to be greater than what is observed.) Separate calculations were made for "warm" runs $\left(\sim 100^{\circ} \mathrm{F}\right)$ and "cold" runs $\left(-250^{\circ} \mathrm{F}\right)$. The row labeled "NTF-162a" includes all three repeat series acquired during the test, whereas the row labeled "NTF-162b" includes only the last two series run after a change in model conditioning procedures.

Table 2 shows that the NTF had excellent warm air characteristics throughout the evaluation period and steadily improving cold (nitrogen) performance, particularly in terms of $\mathrm{C}_{\text {Lmax }}$. The drag numbers are not within the target tolerance; however these statistics are for a landing configuration with highly deflected flaps, a notoriously challenging case for drag repeatability.

The improved repeatability of the aerodynamic force coefficients at cold (cryogenic) conditions is attributable to at least five factors: 1) an increasingly dry testing environment, 2) improved procedures for model and tunnel conditioning, 3) external balance improvements to enhance thermal stability, 4) tighter tunnel control tolerances, particularly with respect to freestream temperature, and 5) a new process for more accurately applying model weight tares obtained at cryogenic temperatures instituted prior to Test-162. 
Table 2. Run-to-Run Force Coefficient Repeatability $\mathbf{9 5 \%}$ Tolerance Intervals

\begin{tabular}{|c|c|c|c|c|c|c|c|c|}
\hline Force Coefficients & \multicolumn{3}{|c|}{ Mid-Rn ( 6M) Warm } & \multicolumn{3}{|c|}{ High Rn ( 24-26M) Cold } & \multirow[b]{2}{*}{$\begin{array}{c}\text { Moisture } \\
\text { Level }\end{array}$} & \multirow[b]{2}{*}{\begin{tabular}{|c|} 
Clmax Extrap to \\
Flight
\end{tabular}} \\
\hline Tests & $\begin{array}{c}\text { CLMAX } \\
95 \% \mathrm{TI}\end{array}$ & $\begin{array}{c}\text { CL6 } \\
95 \% \mathrm{TI}\end{array}$ & $\begin{array}{c}\text { CDP6 } \\
95 \% \text { TI }\end{array}$ & $\begin{array}{c}\text { CLMAX } \\
95 \% \text { TI }\end{array}$ & $\begin{array}{c}\text { CL6 } \\
95 \% \text { TI }\end{array}$ & $\begin{array}{c}\text { CDP6 } \\
95 \% \mathrm{TI}\end{array}$ & & \\
\hline Target $\quad(+/-)$ & 0.010 & 0.010 & 0.0010 & 0.010 & 0.010 & 0.0010 & $<0.1 \mathrm{ppm}$ & $?$ \\
\hline NTF-144 (+/-) & 0.003 & 0.003 & 0.0012 & 0.090 & 0.033 & 0.0015 & $(<20)$ & Asymptotic \\
\hline NTF-145 (+/-) & 0.004 & 0.020 & 0.0025 & 0.032 & 0.073 & 0.0007 & $(<5)$ & Asymptotic \\
\hline NTF-150 (+/-) & 0.004 & 0.009 & 0.0012 & 0.012 & 0.035 & 0.0116 & $(<1)$ & Asymptotic \\
\hline NTF-162a (+/-) & 0.005 & 0.002 & 0.0003 & 0.017 & 0.018 & 0.0035 & $(<1)$ & Mixed \\
\hline NTF-162b (+/-) & & & & 0.010 & 0.010 & 0.0030 & $(<1)$ & Log-Linear \\
\hline
\end{tabular}

The average variation of Mach, total pressure, and total temperature within a run is shown in Table 3. The within run tolerance intervals are averaged over the same sets of repeat runs that were used to evaluate the force coefficients. The data shows that within run test conditions are extremely stable at the NTF.

Table 3. Average Variation of Test Conditions Within a Run 95\% Tolerance Intervals Averaged Over a Set of Repeat Runs

\begin{tabular}{|c|c|c|c|c|c|c|}
\hline Within Run & \multicolumn{3}{|c|}{ Mid-Rn ( 6M) Warm } & \multicolumn{2}{c|}{ High Rn ( 24-26M) Cold } \\
\hline Test Conditions & $\begin{array}{c}\text { M } \\
\text { 95\%TI }\end{array}$ & $\begin{array}{c}\text { Pt (psi) } \\
\text { 95\%TI }\end{array}$ & $\begin{array}{c}\text { Tt (degF) } \\
\text { 95\%TI }\end{array}$ & $\begin{array}{c}\text { M } \\
95 \% \text { TI }\end{array}$ & $\begin{array}{c}\text { Pt (psi) } \\
\text { 95\%TI }\end{array}$ & $\begin{array}{c}\text { Tt (degF) } \\
\text { 95\%TI }\end{array}$ \\
\hline Set Tolerance (+/-) & $\mathbf{0 . 0 0 3 0}$ & $\mathbf{0 . 0 4 0}$ & $\mathbf{5 . 0}$ & $\mathbf{0 . 0 0 3 0}$ & $\mathbf{0 . 0 4 0}$ & 1.0 \\
\hline NTF-144 (+/-) & $\mathbf{0 . 0 0 0 6}$ & $\mathbf{0 . 0 0 1}$ & $\mathbf{0 . 4}$ & $\mathbf{0 . 0 0 0 8}$ & $\mathbf{0 . 0 0 6}$ & 1.2 \\
\hline NTF-145 (+/-) & $\mathbf{0 . 0 0 0 7}$ & $\mathbf{0 . 0 0 7}$ & 1.5 & $\mathbf{0 . 0 0 0 2}$ & $\mathbf{0 . 0 0 1}$ & $\mathbf{0 . 2}$ \\
\hline NTF-150 (+/-) & $\mathbf{0 . 0 0 0 7}$ & $\mathbf{0 . 0 0 7}$ & 1.6 & $\mathbf{0 . 0 0 0 9}$ & $\mathbf{0 . 0 0 3}$ & $\mathbf{0 . 6}$ \\
\hline Set Tolerance (+/-) & $\mathbf{0 . 0 0 1 0}$ & $\mathbf{0 . 0 2 0}$ & 4.0 & $\mathbf{0 . 0 0 1 0}$ & $\mathbf{0 . 0 4 0}$ & 1.0 \\
\hline NTF-162a (+/-) & $\mathbf{0 . 0 0 0 4}$ & $\mathbf{0 . 0 1 0}$ & 1.0 & $\mathbf{0 . 0 0 0 6}$ & $\mathbf{0 . 0 0 5}$ & $\mathbf{0 . 5}$ \\
\hline NTF-162b (+/-) & & & & $\mathbf{0 . 0 0 0 6}$ & $\mathbf{0 . 0 0 5}$ & $\mathbf{0 . 5}$ \\
\hline
\end{tabular}

Note: A "set tolerance" is a facility/customer agreed-to target of acceptable variation of certain key parameters programmed into the data acquisition system.

The average variation of test conditions between runs is shown in Table 4 . The between run statistic is the maximum difference (range) of the average within run value calculated for each run. In other words, whereas the within run statistics are a measure of the variation within a single run, the between run statistics are a measure of how much the average test conditions changed from run to run. The variation is smaller between runs due to the fact that averages are being compared. The between run data shows a significant reduction in data scatter between the 2003 and 2006 test entries. 


\section{Table 4. Variation of Tunnel Conditions Between Runs Maximum Difference (Range) of the Average Values From a Set of Runs}

\begin{tabular}{|c|c|c|c|c|c|c|}
\hline Between Runs & \multicolumn{3}{|c|}{ Mid-Rn ( 6M) Warm } & \multicolumn{3}{c|}{ High Rn ( 24-26M) Cold } \\
\hline Test Conditions & M & Pt (psi) & Tt (degF) & M & Pt (psi) & Tt (degF) \\
\hline Set Tol. (+/-) & $\mathbf{0 . 0 0 3 0}$ & $\mathbf{0 . 0 4 0 0}$ & $\mathbf{5 . 0}$ & $\mathbf{0 . 0 0 3 0}$ & $\mathbf{0 . 0 4 0 0}$ & $\mathbf{1 . 0}$ \\
\hline NTF-144 (+/-) & $\mathbf{0 . 0 0 0 1}$ & $\mathbf{0 . 0 0 0 2}$ & $\mathbf{0 . 4}$ & $\mathbf{0 . 0 0 0 1}$ & $\mathbf{0 . 0 0 0 9}$ & $\mathbf{0 . 6}$ \\
\hline NTF-145 (+/-) & $\mathbf{0 . 0 0 0 1}$ & $\mathbf{0 . 0 0 0 5}$ & $\mathbf{0 . 1}$ & $\mathbf{0 . 0 0 0 0 3}$ & $\mathbf{0 . 0 0 0 5}$ & $\mathbf{0 . 2}$ \\
\hline NTF-150 (+/-) & $\mathbf{0 . 0 0 0 0 4}$ & $\mathbf{0 . 0 2 0 2}$ & $\mathbf{0 . 2}$ & $\mathbf{0 . 0 0 0 2}$ & $\mathbf{0 . 0 0 0 4}$ & $\mathbf{0 . 7}$ \\
\hline Set Tol. (+/-) & $\mathbf{0 . 0 0 1 0}$ & $\mathbf{0 . 0 2 0 0}$ & 4.0 & $\mathbf{0 . 0 0 1 0}$ & $\mathbf{0 . 0 4 0 0}$ & 1.0 \\
\hline NTF-162a (+/-) & $\mathbf{0 . 0 0 0 0 3}$ & $\mathbf{0 . 0 0 0 5}$ & $\mathbf{0 . 0 4}$ & $\mathbf{0 . 0 0 0 1}$ & $\mathbf{0 . 0 0 0 4}$ & $\mathbf{0 . 1}$ \\
\hline NTF-162b (+/-) & & & & 0.0001 & $\mathbf{0 . 0 0 0 4}$ & $\mathbf{0 . 1}$ \\
\hline
\end{tabular}

\section{Low Speed Cryogenic Testing Challenges}

Low speed wind tunnel testing has its own unique challenges which are very different from those encountered in high speed (cruise) testing. Low speed testing requires different test conditions (full polars at $\mathrm{M}=0.2$ to 0.3 versus alpha limited polars at $\mathrm{M}=0.4$ to1.0), a lower dynamic pressures regime $(<100$ to $1000 \mathrm{psf}$ low speed versus $\sim 500$ to $3000 \mathrm{psf}$ high speed), different model construction (multiple wing elements low speed versus a single element high speed wing), and different data corrections. (Although the fundamental types of corrections are basically the same for low speed and high speed testing, the magnitudes of individual correction terms may be different. The short list of corrections common to both speed regimes includes solid blockage, wake blockage, lift interference (upwash), and solid blockage induced buoyancy. The differences in correction magnitudes (and even signs) is due to differences in flight physics: high lift vs. moderate lift levels, large separated wakes vs. small attached viscous wakes, large trailing vortex wake deflections vs. "negligible" deflections, incompressible flow vs. significant compressibility effects with increasing Mach number, and perhaps the wall configuration.) Most low speed testing is done with solid walls, resulting in larger corrections (for solid blockage, wake blockage, and lift interference upwash) than typical slotted walls, which are the most common wall configuration for high subsonic testing. Low speed testing with slotted walls minimizes solid blockage and separated wake blockage, but increases solid blockage induced buoyancy. (The low speed tests described in this paper were all conducted with slotted walls.)

Other low speed versus high speed differences include boundary layer tripping strategies, model mounting, and test plan optimization. For the low speed tests described in this paper, Boeing used semi-span models (with an external balance) to maximize Reynolds number and minimize high lift system bracket blockage, whereas high speed tests in the same facility have typically used full span models with an internal balance. Low speed tests generally require fewer Mach numbers and far more model changes compared to typical high speed tests. Thus, the development of low speed testing procedures at a facility originally designed and used for high speed full span models has been a complex, ongoing task. Two of the most difficult challenges encountered in the course of testing understanding and dealing with moisture effects and improving model change productivity in a cryogenic environment - are discussed below.

\section{Moisture Control}

Moisture control is arguably the number one technical challenge faced by cryogenic wind tunnels today. A trace amount of moisture exists in the source nitrogen $(<<1 \mathrm{ppm})$, and additional moisture contamination can be introduced into the tunnel circuit during tunnel maintenance and/or during model changes. Pre-existing pockets of residual humidity anywhere in the circuit will eventually get absorbed into the working fluid and raise the overall water content. As discussed in Ref. 10, the internal insulation at the NTF captures moisture and releases it back into the circuit over time. To defend against recontamination, the nitrogen in the tunnel circuit is completely exchanged several times, and the moisture level of the air stream is monitored over time to infer the level of moisture remaining in the insulation. Testing does not proceed until the insulation is dry enough to minimize diffusion. Consistent monitoring with established procedures is critical. The frost point of nitrogen is a function of the amount of water 
present (typically measured in parts per million) and the local static pressure. (The term "frost point" is used instead of "dew point" anytime the temperature is below freezing, which is most of the time in a cryogenic wind tunnel.) The local static temperature can drop below the frost point in both high and low speed tests. In a high speed test, Cp's are relatively low, but the freestream Mach number is high; whereas in a low speed test, the freestream Mach number is relative low, but $\mathrm{Cp}$ 's are high. In both cases, the local conditions can be transonic. At 3 atmospheres and $1 \mathrm{ppm}$ (by volume), the frost point is $-92^{\circ} \mathrm{F}\left(-69^{\circ} \mathrm{C}\right)$; while at 3 atm and $0.10 \mathrm{ppm}$, it drops to around $-120^{\circ} \mathrm{F}\left(-84^{\circ} \mathrm{C}\right)$. Because cryogenic wind tunnels operate at freestream total temperatures as low as $-250^{\circ} \mathrm{F}\left(-157^{\circ} \mathrm{C}\right)$ and local static temperatures can drop below $-300^{\circ} \mathrm{F}\left(-184^{\circ} \mathrm{C}\right)$ in regions of very low static pressure, there is risk of frost contamination on the model over a significant fraction of the test envelope. Even small levels of distributed roughness due to frost can have a significant effect on the aerodynamic characteristics of a model, particularly at or near $\mathrm{C}_{\mathrm{Lmax}}$. The frost issue is dealt with at the NTF in three ways: prevention, detection, and removal.

\section{A. Prevention}

Over the years, the NTF has developed a number of procedures to ensure that the test environment is as dry as possible. One of the most effective is to regularly cycle dry air through the circuit to absorb and expel excess moisture any time the circuit is not being used for testing. A continuous effort to maintain low moisture levels has proven to be an important part of the moisture control process. During testing, purge cycles are used to keep the tunnel below established moisture thresholds. The higher the temperature (and the lower the pressure) the more moisture can be absorbed and purged in a given cycle. Each subsequent cycle lowers the overall moisture content until target levels $\left(10 \mathrm{ppm} \text { at } 20 \mathrm{psia} \text { and } 100^{\circ} \mathrm{F}\right)^{8}$ are reached. The cooldown process is then initiated. After cooldown and pressurization, the introduction of fresh nitrogen further lowers the moisture content to around 1 to $5 \mathrm{ppm}$. Once target levels are reached, there are two possible sources of recontamination: 1) continued outgassing (diffusion) of residual moisture from deep in the tunnel insulation and 2) moisture introduced as a consequence of access to the model. The first of these is dealt with by using a dynamic dryness criterion to determine when the tunnel is dry enough for testing. The dynamic criterion is based on the rate of change of the moisture level over an extended time period. Moisture introduced during model changes is prevented by isolating the model from the rest of the circuit using a newly developed semi-span model access housing. The access housing can be purged with dry nitrogen before being removed, thus limiting contamination of the tunnel circuit. These procedures have been shown to greatly reduce the risk of frost on the model. It should be kept in mind, however, that it is physically impossible to remove $100 \%$ of the moisture from the working fluid because some amount of water is inherent in the source nitrogen and it is extremely difficult to fully dry the tunnel insulation. Any residual moisture will condense out when and where the conditions are right. At a dryness level of $1 \mathrm{ppm}$ by volume, for example, the 230,000 cu ft volume of the NTF will only retain a tenth of an ounce of water in the gas stream; however, experience has shown that even at those extreme dryness levels, small amounts of frost can still form on the model. With this knowledge, procedures have been developed to ensure that even if frost conditions exist in the tunnel circuit, frost contamination is avoided on the model.

\section{B. Detection}

If frost contamination cannot be avoided, then identification and removal are critical. Identification can be made indirectly (by inference) by tracking $\mathrm{C}_{\mathrm{Lmax}}$ and/or drag trends over multiple repeat runs or series or directly, in real time, by visual observation or other quantitative means. Whereas gross frost effects tend to be nonrepeatable, mild frost can be very subtle. Of all the technologies involved in cryogenic testing, direct (quantitative) frost detection is one of the most difficult. The simplest qualitative method is to point a high resolution camera at the model, thereby providing a means for detailed observation. If frost forms, it can sometimes be seen as a subtle change in color or reflectivity of the model surface, occasionally with visible wakes behind protuberances such as brackets and/or vortex generators. The visual method is highly dependent on lighting and camera angle, and as the tunnel environment gets drier, the method gets more difficult and less reliable. New, more sensitive quantitative techniques are needed.

\section{Removal}

If frost is detected on the model, it must be removed before testing can continue. Unfortunately, the usual remedy applied to high speed models - scrubbing the frost off at high dynamic pressure - is not available for low speed models due to load limits on the leading and trailing edge brackets. For example, at $4 \mathrm{~atm}$ and $\mathrm{M}=0.85$, a high speed model might be subjected to a dynamic pressure (Q) of around $2700 \mathrm{psf}$; whereas at the same total pressure and $\mathrm{M}=0.21$, the $\mathrm{Q}$ on a low speed model is only $254 \mathrm{psf}$, less than one-tenth of the high speed value. The nature of 
low speed models (flaps and slats supported by brackets) makes it impossible to design a model that can withstand the high dynamic pressure required to scrub frost off in this way, and because aerodynamic heating due to energy input from the drive fan is the most effective way to warm the tunnel, this same dynamic pressure restriction also affects how much the tunnel can be heated up during purge cycles. The net result is that two of the best tools to remove frost (high $\mathrm{Q}$ and high temperatures) are not usable for low speed tests. Fortunately, now that the semi-span model access housing is available, it is possible to warm the model to a temperature above the frost point and remove any residual frost with far less impact to schedule than previously required.

\section{Monitoring}

The tracking of moisture levels in a cryogenic wind tunnel is a science unto itself and must be done consistently using standard processes. At the NTF, a single static measurement is not sufficient to characterize the dryness of the facility, because it does not reflect the rate of discharge (outgassing) from the tunnel insulation. Engineers at the NTF have learned that consistently dry test conditions cannot be maintained until the outgassing from the insulation has been reduced to minimum levels. Monitoring moisture is complicated by the fact that conventional dew point meters are accurate only down to about $-100^{\circ} \mathrm{F}(1 \mathrm{ppm}$ at $\mathrm{Pt}=20 \mathrm{psia})$. At $0.1 \mathrm{ppm}$ and $\mathrm{Pt}=20 \mathrm{psia}$, the dew point is $126^{\circ} \mathrm{F}$ (too low to be accurately measured). The NTF is investigating a new type of sensor accurate to $-140^{\circ} \mathrm{F}(0.02$ $\mathrm{ppm}$ at $\mathrm{Pt}=20 \mathrm{psia})$.

\section{E. Moisture Lessons Learned}

1. Moisture cannot be reduced below what is inherent to the source nitrogen.

2. Local conditions on the model may be conducive to frost contamination any time the tunnel is cold.

3. The tunnel is "dry enough" only after diffusion from insulation has been reduced to an acceptable rate.

4. The diffusion rate must be tracked using a consistent process.

5. Because frost conditions cannot be avoided, even at moderate cryo temperatures, model contamination must be avoided using established model and tunnel conditioning processes.

6. When appropriate measures have been taken to avoid frost contamination, quality data are achievable.

\section{VIII. $C_{\text {Lmax }}$ Reynolds Number Trend}

Undoubtedly, the most interesting development over the course of the 777 and 787 low speed testing was the emergence of a log-linear $\mathrm{C}_{\mathrm{Lmax}}$ vs. Rn trend in the second phase of NTF-162, compared with the "asymptotic" trend seen in previous cryogenic tests. Prior to NTF-162, the $\mathrm{C}_{\mathrm{Lmax}}$ trend with Reynolds number has always tended to flatten (or reverse) as flight values are approached. It has been a matter of conjecture whether or not this "adverse Rn effect" is real or an artifact of some other variable. During the last two series of NTF-162, after a change in the tunnel conditioning process, the $\mathrm{C}_{\mathrm{Lmax}}$ trend became log-linear all the way to flight Reynolds number (as illustrated in Fig. 4).

It is interesting to note that the moisture level did not change significantly between the first series (asymptotic Rn trend) and the last two series (log-linear trend), nor did Mach, total pressure or total temperature. Although no frost contamination was visible during any of the series, it is possible that frost conditions may have been present and contamination of the model was averted in the second and third series due to the improved "frost avoidance" procedures; i.e., more rigorous model and tunnel conditioning. The final determination on how well the wind tunnel data characterize flight performance will follow flight testing of

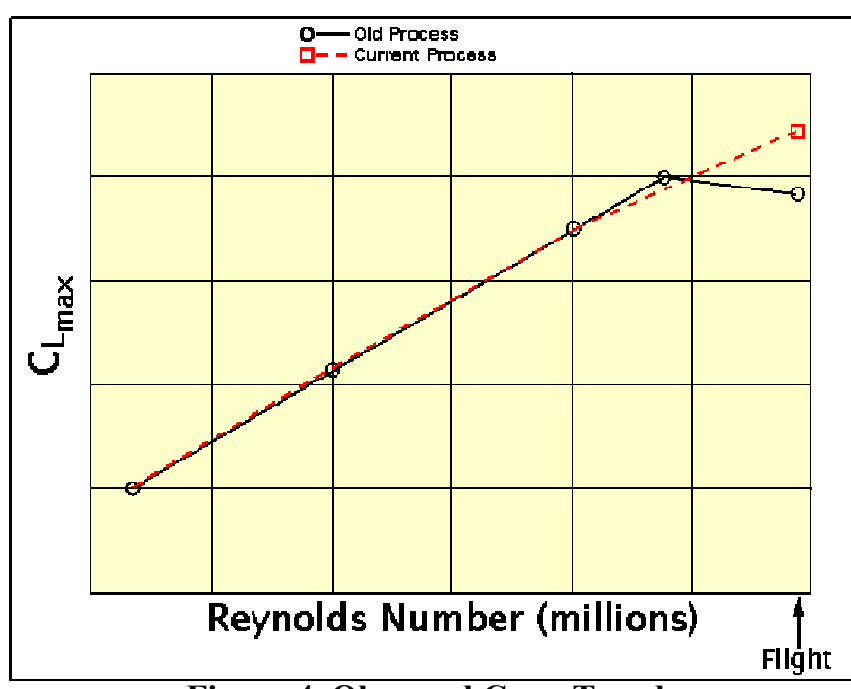

Figure-4. Observed $C_{\text {Lmax }}$ Trends the 787-8 aircraft in 2007-2008. 


\section{Productivity in the Cryogenic Test Environment}

Today, the only reasons not to test at the highest Reynolds number possible are related to cost and cycle time. Cryogenic testing is expensive and time consuming and airplane development budgets are limited in both respects. Although low speed testing productivity has improved dramatically at the NTF since the access housing for semispan models became available, cryo tunnels have a long way to go before they catch up with conventional pressure tunnels in productivity (an admittedly unfair comparison due the difficulty of working in the cryogenic environment). Metrics gathered during the course of the 777 and 787 testing are shown in Table 5. (More details were tracked during NTF-162 than the earlier tests.) The tracking of detailed customer productivity metrics ${ }^{11}$ marks a paradigm shift in thinking of a cryogenic tunnel as a practical design tool rather than a research facility and is the first step in improving performance. In recent years the NTF has been very active in pursuing productivity-related improvements, including the previously discussed semi-span model access housing, a recirculating drier for moisture control, improved plenum venting, and extended shift operations. The initial implementation of the semispan access housing in NTF-150, for example, still required warming the tunnel to a minimum of $-100^{\circ} \mathrm{F}$ before the model could be accessed. In NTF-162, model access occurred with the tunnel at temperatures as low as -250F, thus providing additional time savings. As Table 5 illustrates, the cumulative effect of these improvements has increased productivity at the facility dramatically. The time required to make a model change has been cut by almost $80 \%$ and the average number of test series per day has more than doubled.

Table 5. Low Speed Productivity Metrics

\begin{tabular}{|c|c|c|c|c|c|}
\hline Metric & NTF-144 & NTF-145 & NTF-150 & NTF-162 & Comment \\
\hline Polars Per Fan On Data Acquisition Hour & n.a. & n.a. & n.a. & 7.05 & Polars/Time on Condition \\
\hline Polars Per Fan-On Hour & n.a. & n.a. & n.a. & 0.69 & $\begin{array}{l}\text { Polars/(Time on Condition }+ \\
\text { Conditioning Time) }\end{array}$ \\
\hline Percent of Runs in Cryo (LN2) Mode & $\mathbf{5 0 \%}$ & $78 \%$ & $100 \%$ & $100 \%$ & \\
\hline Average Polars per Cryo Series & 32.5 & 9.5 & 11.7 & 5.7 & \\
\hline Cryo Series Per Typical Calendar (Work) Day^ & 0.20 & 0.36 & 0.43 & 0.70 & $\begin{array}{l}\text { A series is a set of runs between model } \\
\text { changes }\end{array}$ \\
\hline Cryo Series Per Total Calendar Day^ & 0.17 & 0.33 & 0.24 & 0.44 & Includes weekends and holidays \\
\hline Average Cryo Model Access Cycle Time (Hrs) & $46^{*}$ & $64 *$ & 30 & 10 & $\begin{array}{l}\text { All temperatures wind-off to wind-on } \\
\text { minus model work }\end{array}$ \\
\hline Average Cryo Model Change Time (Hrs) & n.a. & n.a. & n.a. & 2.3 & All temperatures hands on to hands off \\
\hline
\end{tabular}

^ Does not include installation

* Pre-Semispan Model Access Housing

\section{Conclusions}

The development of low speed cryogenic test techniques at the NTF has been an exciting and technically challenging process. Significant advances have been made in the areas of semi-span test techniques, the external (side wall) balance, wall corrections, model access, and moisture control. Initial results from the most recent 787 low speed test show a never-before-seen log-linear trend with Reynolds number up to full flight, a result which will be compared with flight trends in the 2007-2008 time period after commencement of 787 flight testing. The combination of data quality and productivity-related improvements at the NTF is expanding the realm of cryogenic testing from pure research into the product development sphere. If history is a guide, this trend is likely to continue.

\section{Acknowledgments}

The authors would like to acknowledge Allen Kilgore and Richard Wahls for their unfailing and energetic support of process improvement at the NTF. Their efforts and those of the entire NTF staff are laying the groundwork for the future of flight Reynolds number wind tunnel testing. 


\section{References}

[1] Payne, F. M., Wyatt, G.W., Bogue, D.R.; and Stoner, R.C., "High Reynolds Number Studies of a Boeing 777-200 High Lift Configuration in the NASA ARC 12' Pressure Tunnel and NASA LaRC National Transonic Facility," AIAA-2000-4220, Reno, Nevada, U.S.A., January 2000.

[2] Lynch, F.T., "Experimental Necessities for Subsonic Transport Configuration Development," AIAA-92-0158, Reno, Nevada, U.S.A., January 1992.

[3] Milholen, W. E., Chokani, N., and McGhee, R. J.; "Development of Semispan Model Test Techniques," Journal of Aircraft, Vol. 33, No. 6, 1996, pp. 1115-1122.

[4] Gatlin, G. M., and McGhee, R. J., "Experimental Investigation of Semispan Model Testing Techniques," Journal of Aircraft, Vol. 34, No. 4, 1997, pp.500-505.

[5] Milholen, W. E., "Design Methodology for Semispan Model Mounting Geometries," AIAA-98-0758, Reno, Nevada, U.S.A., January 1998.

[6] Gatlin, G. M., Parker, P. A., and Owens, L. R., "Development of a Semi-span Test Capability at the National Transonic Facility," AIAA-2001-0759, Reno, Nevada, U.S.A., January 2001.

[7] Gatlin, G. M., Parker, P. A., and Owens, L. R., "Advancement of Semispan Testing at the National Transonic Facility," Journal of Aircraft, Vol. 39, No. 2, 2002, pp. 339-353.

[8] Gatlin, G. M., Tomek, W. G., Payne, F. M.; and Griffiths, R. C., "Recent Improvements in Semi-span Testing at the National Transonic Facility," AIAA-2006-508, $44^{\text {th }}$ AIAA Aerospace Sciences Meeting and Exhibit, Reno, Nevada, U.S.A., January 2006.

[9] Payne, F. M., "Low Speed Wind Tunnel Testing Facility Requirements: A Customer's Perspective," AIAA-99-0306, Reno Nevada, U.S.A., January 1999.

[10] Gloss, B, and Bruce, R, “A Solution to Water Vapor in the National Transonic Facility," AIAA-89-0152, AIAA, Reno Nevada, U.S.A., January 1989.

[11] Griffiths, Robert C, and Wright, M.C.N., "Performance Testing with High Productivity in a Low Speed Flight Reynolds Number Test Campaign," ICAS 2006, 25 ${ }^{\text {th }}$ International Congress of the Aeronautical Sciences, September 2006. 